\title{
THE SCIENCE OF URBAN DESIGN?
}

\section{Kim Dovey and Elek Pafka}

\begin{abstract}
In a provocative paper Marshall (2012) suggests that a range of seminal urban design theories stemming from the 1960s - Jacobs, Alexander, Lynch and Cullen - can be construed as pseudoscience because they haven't been tested empirically. Adding Sitte and Cerdá, we take this provocation as a chance to raise some questions about the nature of urban design knowledge, theory and practice. We suggest that this work is not and cannot be empirical science but is based in the detailed observation of cities using multiple logics. While there is an emerging science of cities, urban design knowledge is much broader, spanning both natural and social sciences as well as the arts and humanities. We also argue that it is a particular form of diagrammatic socio-spatial knowledge that cannot be reduced to either words or numbers. These thinkers remain seminal more for the questions they open than the answers they provide.
\end{abstract}

\section{Introduction}

In his paper 'Science, pseudo-science and urban design' Stephen Marshall (2012) argues that a series of seminal urban design theory texts might be considered pseudo-science in the sense that they seem to have a testable scientific basis but upon examination they turn out to be untestable or (where they have been tested) false. In a similar vein Lampugnani (2012) calls for a scientific foundation for the field of urban design and Batty (2013) celebrates the emergence of a new science of cities that incorporates urban design. Marshall's paper examines four key texts: Lynch's 'The Image of the City' (Lynch, 1960), Cullen's 'Townscape' (Cullen, 1961), Jacobs' 'The Death and Life of Great American Cities' (Jacobs, 1961) and Alexander's seminal paper 'A City is Not a Tree' (Alexander, 1965). We do not contest Marshall's main arguments - that such theory often appears to make empirical claims, that such claims are often untestable (therefore not science), and that to the degree that they are testable then they should be tested. We suggest, however, that some of such testing is itself a form of pseudo-science. Our goal here is to pursue some of the questions that are opened up, particularly the question of the degree to which urban design theory can and should be considered a science.

We will deal with this through a critique of the specific sets of ideas and concepts derived from Lynch, Cullen, Jacobs and Alexander. In order to understand the roots of such urban design theory we begin with a discussion of two $19^{\text {th }}$ century predecessors - Camillo Sitte and Ildefonso Cerdá. Sitte is widely seen as a precursor of Cullen and Cerdá's theoretical work can be seen to prefigure that of Jacobs. We cannot cover all the work of these writers here, nor compare them in any detail; our goal is to raise questions about the nature of urban design knowledge, theory and practice. How does theory work in a field that ranges from the mathematics of urban morphologies and the sociology of public space to the interpretation of design quality or aesthetic value? We will suggest that while there is an emerging and promising science of cities, urban design knowledge is much broader, that it is a particular form of diagrammatic socio-spatial knowledge that cannot be reduced to either words or numbers. These seminal texts of the 1960 s and earlier are dated in many ways but they remain valuable for the questions they open as much as the answers they provide. 


\section{Sitte and Cullen}

Sitte was one of the most influential early thinkers who aimed to establish urban design as a discipline joining art with science. His major book entitled 'City Building According to Artistic Principles' (1889) had the goal to rescue urban planning from the traffic engineers, to revive an aesthetic of city planning that geared it to the pleasures of everyday life in public space. Urban design was a human-centred task, a science as well as an art (Ley, 2007). Sitte's understanding of art was strongly linked to the study of human perception. Inspired by the writings of Fechner, the founder of psychophysics, Sitte explored the relationship between urban spatial and human perception (Wilhelm 2006, p.40). He wanted to extract essential principles of urban design that run deeper than design style.

A large part of the book is dedicated to the systematic study of contemporary and historic typomorphologies of urban squares in Europe. His method resembles that of 18th and19th century morphological classifications in the natural sciences (Wilhelm, 2006, p.38). While linking morphologies to visual perception Sitte's main preoccupation is with legibility and the picturesque cityscape (Collins and Collins 1965, pp.50-51). He was fascinated by perspective and a conception of urban space as a form of theatre. Sitte's approach involved an implicit critique of the role of public space in the legitimation of power in that he opposed monumentalist urban planning that focused on free-standing buildings and monuments. He argued that squares and plazas should be enclosed with the centre kept free for the life of the city; the size should relate to that of the surrounding buildings with a reciprocal relation between architecture and public space.

Sitte was also concerned with the smaller street networks and buildings of the city and was famously opposed to the regular grid in favour of the informal morphologies of medieval street networks. While these observations have been dismissed as subjective and romantic, they were argued on the basis of both picturesque effect and the ways the character of urban space was formed by evolutionary adaptation. While the book's success has been attributed to the clarity of the writing and diagrammatic maps, Sitte considered its success to be an indication that his theories resonated with the perceptions of the broader public. The influence of Sitte's work diminished during the early 20th century when it was misinterpreted as 'medieval romanticism', based in part on a misleading French translation (Collins and Collins, 1965). From the mid-20th century a more nuanced reading of his work brought Sitte's morphological and phenomenological contribution to urban design theory again into attention. Consequently he was seen as a precursor of a 'critical urbanism' that conceives cities as socio-spatial phenomena (Wilhelm 2006, pp.8688).

This mid-20th century interest in Sitte's work was paralleled by Gordon Cullen's Townscape (1961) (Larice and Macdonald, 2013), and the later German edition of Townscape (Cullen, 1991, translated by Gerhardt) referred to its author as the "Sitte of the 1960s". While he is best known for Townscape, Cullen's preoccupation with the visual perception of urban space and the concept of 'serial vision' date back to the articles he had published since 1947 in The Architectural Review (Gosling, 1996). Cullen's work is avowedly aesthetic rather than scientific: "we have to rid ourselves of the thought that the excitement and drama that we seek can be born automatically out of the scientific research and solutions arrived at by the technical man... We naturally accept these solutions but are not entirely bound by them..." (Cullen 1961: 10). For Cullen the evidence for urban design quality is the visual experience of the city. By the concept of 'serial vision' Cullen seeks to understand the complex ways in which urban experience unfolds for the mobile subject, arguing that a diversity of different forms and spaces experienced over time enriches the emotional and aesthetic impact of the city. This was particularly focused on differences of openness and enclosure as one moves through narrow pathways and small public spaces towards grand open spaces and vistas. 
Rapoport and Kantor's (1967) examination of Cullen's work found it to be congruent with contemporary research in psychology that showed that humans prefer somewhat structured yet ambiguous and complex visual environments, rather than entirely monotonous or chaotic ones. While there have been further attempts to test this in detail based on historical morphological analysis (Rapoport, 1990) and comparative phenomenological analysis (Isaacs, 2000), the limitations of such studies are so wide-ranging (sample size, cultural differences, complexity of the studied phenomena) that the results can only be interpreted as supportive of the theory rather than scientific proof.

There is also a further problem in that there are clear limits to any science of aesthetics. Suppose we could prove empirically that people generally prefer certain cityscapes, urban imagery or open space designs - this won't persuade those who accuse Sitte and Cullen of romanticism because such critique stems from the humanities and not the sciences. Theories of the picturesque can only be tested by reducing the city to a picture, and it is this reduction that is at the heart of the critique of the picturesque (MacArthur, 2007). The attempt to create such streetscape effects through urban design can easily fall into a production of formularized picturesque scenography.

\section{Lynch}

While Lynch's work on urban design theory is very broad the primary work under discussion here is that on the image of the city comprised of the set of five elements - nodes, paths, edges, districts and landmarks (Lynch 1960). In the preface Lynch acknowledges the debt to his mentor Gyorgy Kepes, who co-directed this research at MIT in the 1950s. Kepes is the painter and art theorist who argued for a universal 'Language of Vision' (Kepes, 1944) and was strongly influenced by German gestalt psychology. The 'gestalt' is a pattern or a whole that emerges as more than the sum of its parts, where parts and wholes are co-dependent - we don't simply perceive an objective world, rather we organize parts to construct wholes (Arnheim, 1954). Lynch's quest is to articulate universal patterns of experience and perception, based in elements of urban morphology.

Two separate research methods were used by Lynch: a detailed mapping of the subject areas by trained observers, and in-depth semi-structured interviews with residents (Lynch 1960:

Appendices). Interviewees were asked to identify elements of the city and their boundaries; their responses were then analysed according to the typology of landmarks, paths, edges, nodes and districts. This typology appears to be the framework for analysis rather than a finding that emerges from the interviews; it is a hypothesis that is confirmed by the data. In other words the elements largely derive from gestalt theory as the wholes that emerge from the parts, figures against the ground of the urban fabric. Landmarks mark the land, districts are patches of consistent character, nodes are junctions and crossings of paths, paths are lines of movement and edges are barriers to movement. This typology has become seminal, not because it was affirmed empirically, but because it resonates with a gestalt 'language of vision' to use Kepes' phrase, with a universal practice of urban cognitive mapping.

Conceptually the elements are a mix of centres (landmarks, nodes), lines (paths, edges) and territories (districts). What unites them is that they are all perceptual wholes that interact to form the image of the city. They all draw upon gestalt perceptual tendencies to construct identities out of differences. The question of the degree to which a particular building figures as a landmark in the image of the city can be tested empirically (if such a fact were valuable) but the question of the validity of the category of the landmarks as a primary element of urban cognition is of a different order. The primacy of figures that mark the land and our pathways across it can be deduced from gestalt theory. Lynch's elements were picked up in practice because they resonate so well with the urban phenomenology of everyday life - we navigate streets, past intersections and landmarks, across boundaries and through different neighbourhoods. 
This set of elements, however, is also problematic. The closer one looks the more the boundaries between 'elements' blur and intersect in a manner that dissolves the differences between them. A node is defined as an intersection of paths and is often also a district. A major path may become a district or an edge to a district. Some elements become others through the effects of scale, as when a path at metropolitan scale (freeway) becomes an edge at neighbourhood scale. There is no objective sense in which this is a complete set of elements. Lynch includes the urban plaza or enclosed void within the urban fabric as a node (Lynch 1960: 78), however, if the study were based on European cities there may have been an additional element of the urban void (more than just the inverse of the landmark). If the analysis were based on Asian cities there may be a different set again.

Lynch's theory becomes problematic when the line is crossed from urban design theory to practice; when we move uncritically from the question of 'what makes the city legible?' to 'how to make the city legible?'. Legibility is the degree to which spatial orientation within the city is accessible to outsiders - a legible city will show a stronger correlation of cognitive mapping between insiders and outsiders. Legibility makes the city easy to learn but it is scarcely an unmitigated good. Cullen's notion of serial vision celebrates the aesthetic of illegibility, or at least the joys of discovering the city one street and place at a time. Lynch suggests 'there is some value in mystification, labyrinth, or surprise...but only where there is no danger of long-term disorientation '(1960: 5-6). Yet the long-term danger of the quest for legibility, beyond the boredom of formularized urban design, is that we misrecognize these perceptual wholes as parts; that we seek to build the legible city out of a kit of parts - paths, nodes, landmarks, districts and edges - while forgetting that they are the emergent wholes.

There is another key reason why Lynch's categories are not a form of science. While Lynch recognizes that one cannot separate urban cognition from questions of meaning, this work barely scratches that particular surface. While there is no scope here to pursue such questions, urban landmarks clearly have potency as symbolic and political capital; nodes and districts are sites of intensive social encounter; and edges are forms of social segregation. These are questions for the humanities and are rarely empirical questions.

\section{Cerdá}

Ildefonso Cerdá is mainly known as the designer of Barcelona's 19th century extension and the person who coined the term "urbanization". Less known is that between 1855 and 1876 he produced a vast oeuvre of urban theory that was in part based on systematic socio-spatial surveys, morphological analysis and observation-based insights into cities that he understood as complex movement economies with synergistic relations between their components (Soria y Puig, 1999). Cerdá's explicit intention was to establish a multi-disciplinary science of cities that relied upon political economy, social science and philosophy among other disciplines (Soria y Puig, 1999, pp.64-66). This approach attracted broad disapproval from the local elite who considered city building to belong to the realm of art. This conflict, along with the gradual socio-political exclusion he was subjected to, is seen as one of the reasons why his work has been buried in archives for a century (Soria y Puig, 1999, pp.37-40) and as a result remained for so long inconsequential in the history of urban theory (Choay, 1997). Until today most of his work is only accessible to Spanish speakers with the exception of fragments included in the anthology by Soria y Puig (1999).

One of Cerdá's most comprehensive empirical undertakings was a statistical analysis of Barcelona which then comprised 518 urban blocks with a population of over 190,000. He examined the correlations between the number of deaths by cholera between 1856 and 1865, their location of residence (district, city block) and urban form (storey, street orientation and gross block density). While hygienist theories of the time suggested that mortality by infectious diseases correlate with density, Cerdá's study showed a correlation instead with social status. However, only the raw data 
was published and the implicit conclusions of the survey were not made explicit (Soria y Puig, 1999, pp. 270-273). The false association of density with morbidity continued to influence urban design until its rebuttal in the 1960s and '70s (Mitchell, 1971; Cohen and Sherrod, 1978).

While Cerdá attempted to ground his theory on verifiable empirical evidence, he understood that cities are made of complex interrelationships between multiple urban elements and that groupings of elements lead to emergent effects that couldn't be simply explained as the sum of the parts. He also understood that any change to one element can lead to divergent effects overall (Serratosa, 1999). He meticulously considered the advantages and disadvantages of a large range of urban forms including street length and width, block shape and size, orientation, intersection configuration, building coverage and height. Yet when designing he ultimately relied upon umbrella concepts of egalitarianism and political justice. Many elements of the Barcelona extension plan such as the regular grid, square blocks, 45 degree orientation to the cardinal points, uniform street width were a result of the aim to create an urban structure that provided equality of opportunity without pre-established formal hierarchies. Cerdá wasn't concerned with such an approach leading to monotony as differentiation would inevitably occur in unregulated aspects of built form, such as building height, façade design and socio-spatial patterns. While relatively uniform height limits were imposed by the city council, a review of Barcelona's evolution in the past century shows diversification of urban form - some blocks are divided by shortcuts, some courtyards have become public parks or are covered, and there is a diverse functional and social mix throughout the grid (Barcelona City Council, 2010).

Apart from his investigation of hygienist theories and urban morphology, perhaps the main thesis in Cerdá's 'general theory' is that streets as connections between people and buildings constitute the basis of urbanization (Soria y Puig, 1999, p.103). At the larger scale, cities were defined as nodes "along the universal economy of ways" (Soria y Puig, 1999, p.115) preceding Hillier and Hanson's (1984) concept of cities as 'movement economies' by over a century. Cerdá's concept of a synergy between streets, buildings and people was reflected in two further neologisms he coined: 'viality' that combined street (via) with vitality and 'inteways' that referred to building blocks being defined by streets. These concepts were not the result of scientific testing, but rather a result of his observations of the dynamic nature of 19th century cities.

Cerdá's unfinished General Theory of Urbanization (1867) is similar to other 19th century approaches by individual authors to systematically draw together and connect various fields of knowledge that can lead to a better understanding of cities. For example in Germany the treatises of Baumeister (1876) on 'city extensions' and Stübben (1890) on 'city building' are seen as similar attempts to develop a basis for a scientific approach to urban design (Ley, 2007). Similarly, these German works haven't been translated, and seem to have had limited impact. In recent years this led to critiques that parallel Marshall's, of a lack of scientific underpinning of contemporary urban design theory as well as of the risk of being marginalised by other fields of science (Lampugnani, 2012).

\section{Jacobs}

The urban design work of Jacobs is probably the best known of any of these theorists and Marshall is correct to suggest that much of the literature about this work is superficial and there is little empirical testing. Her insights are largely based on personal observations of the streets of Greenwich Village as contrasted with other parts of New York - the uses of sidewalks, place ballet, eyes on the street, the importance of the public interface all comes from there. The key ideas that are of concern here are the principles of permeability (short blocks), functional mix, formal mix (old buildings) and density (concentration) that she argues are necessary conditions for the good city. This body of theory, with substantial elaborations and a new language, is perhaps the most robust piece of theory within the field of urban design. But is it scientific and to what degree might it be tested? 
Marshall points to the work of Weicher and Schmidt as examples of the scientific testing of Jacobs' theory that have to some degree disproven it. Weicher $(1973$, p.29) began with the claim that "Jacobs' theory [...] can easily be reformulated in mathematical terms" and "much of the data needed for empirical investigation is readily available". Average measures for functional mix, age of buildings, block size and density were collected for a range of districts across Chicago and compared with measures for social dysfunction such as crime and health. He found that Jacobs's principles correlated to some degree with social dysfunction. Weicher's study, however, was poorly conceived and implemented. The districts ranged from 2.5 to $23 \mathrm{sq} \mathrm{km}$, with a median of about $8 \mathrm{sq} \mathrm{km} \mathrm{-} \mathrm{a} \mathrm{scale} \mathrm{that} \mathrm{Weicher} \mathrm{(1973,} \mathrm{p.33)} \mathrm{considered} \mathrm{"the} \mathrm{closest} \mathrm{available} \mathrm{approximation}$ to Jacobs' concept of city district or neighbourhood" yet the largest of these districts are clearly not 'neighbourhoods'. Functional mix was quantified by simply measuring land area allocated to formal planning zones with the maximum mix achieved when residential land is equal to the total of all other categories. This formula does not derive from Jacobs; it ignores both floor area and the vertical dimension of functional mix (such as shop-top housing). Some of these problems are due to a lack of consistent data, but it underlines the dangers of the leap into mathematical testability. The need for effective metrics and mapping of functional mix remains one of the key issues for urban design (Hoek, 2008; Nes et al, 2012), however, Jacobs' argument for the importance of functional mix cannot be tested in this manner. For the criteria of short blocks (permeability), Weicher measured the average area of blocks. This means that the elongated blocks of 60x240m in Chelsea referred to by Jacobs as barriers to neighbourhood access would have an identical score to $120 \times 120 \mathrm{~m}$ blocks in Weicher's index. There are many metrics for permeability and average block area is one of the worst (Pafka and Dovey, forthcoming). When quantifying the mix of old and new buildings, Weicher identified only pre-1940 and post-1940 buildings. Thus a neighbourhood developed during the mid-twentieth century would appear as more diverse than one with many layers between 1860-1940. The need for concentration is the only condition for which Jacobs indicated a neighbourhood-wide measure of density, and here Weicher simply followed Jacobs and made the same mistake. The measure of dwellings/hectare is a poor indicator of the density of residents because it does not account for major differences in household size (Pafka, 2013), especially relevant for socially segregated Chicago neighbourhoods. The poor health and crime outcomes that Weicher found in inner-city Chicago are unlikely to have much connection to urban design.

Schmidt (1977) applied the same methodology used by Weicher to the city of Denver, with improvements (smaller statistical areas, broader categories of crime and disease, four categories of building age) but the same shortcomings and leading to similar false conclusions. We suggest that rather than accusing Jacobs of pseudo-science, these tests of her theory can be considered pseudoscientific in that they bask in the scientific aura of mathematics, while failing to meaningfully link empirical measures with Jacobs' urban design concepts. Even if the data were not so poor, expecting to find linear correlation through multi-variate regression analysis is not consistent with Jacobs' theory which argues that the variables have complex synergistic effects.

Jacobs' argument for functional mix is not about zoning but the ways in which different activities co-function, form alliances and synergies. The formal mix of old and new buildings embodied in the 'old buildings' principle is geared to the mix of building sizes and types necessary to house a multiplicity of functions. This is in turn linked to a mix of rental values and social classes. These multiple conceptions of diversity are interconnected within Jacobs' work and show it to be a series of co-functioning principles each of which is necessary but insufficient to produce the synergistic effects.

The search for linear relationships between these measures is not a test of Jacobs' theory, as she did not imply such linearity. In her final chapter 'The kind of problem a city is' she alludes to emerging work on cybernetics, complexity and information theory that she suggests holds potential for a better understanding of the synergistic effects of cities. This is the work that has evolved into complex adaptive systems theory and resilience thinking; Jacobs fits well into this 
lineage and in terms of cities must be considered one of its greatest early thinkers.

The key arguments here do not rely on empirical testing; mix and density both shorten the average distance between attractions, just as permeability increases access. We have argued elsewhere for the need to develop better metrics than Jacobs does for understanding density - to distinguish building vs population densities, housing vs job densities, internal vs streetlife densities and so on (Dovey and Pafka, 2014). However, we must not confuse this with a test of whether density shortens distances.

\section{Alexander}

Christopher Alexander, who was educated in both science and architecture, has long been engaged in a quest to understand the relations between art and science in architecture and urbanism. His PhD, published as 'Notes on the Synthesis of Form' (1964), was an attempt to develop a rigorous design method that would achieve a better fit between a form and its context. The context was seen to define a problem and the form was the solution. The ensemble of form+context was seen as a 'system' and this was an early form of systems thinking in design - he was looking for the deep generative structures of design. He saw what he termed the 'fitness' of form as a result of multiple adaptations that emerge over time in the 'unselfconscious' production of indigenous architecture and urbanism. The task he took on was to develop a self-conscious understanding of this 'generative' process, the set of rules that generates built form. He was inspired in part by the information sciences of the mid- $20^{\text {th }}$ century - the cybernetics of Weiner (1948) and Ashby (1960) - but also by theories of art and gestalt psychology (Gomrich, 1960; Arnheim, 1954).

'Notes...' was a much celebrated book and a new field of 'design methods' emerged around the promise of a new science of design - a systematic analysis of design into sets and subsets of constituent parts in largely hierarchical formations. Alexander saw design as a process where aesthetic and material issues were diagrammatically linked to social and environmental concerns. The 'diagram' is the key concept to emerge in 'Notes...' - an abstract conception of a set of productive forces operating in a particular situation:

"Le Corbusier's ville radieuse is a diagram which expresses the physical consequences of two very simple basic requirements: that people should be housed at high overall density, and that they should yet all have equal and maximum access to sunlight and air" (Alexander, 1964: p.85)

He distinguishes between 'form diagrams' that show formal outcomes (such as Corbusier's drawings) and 'requirement diagrams' that show only properties, flows and constraints. He argues that only when design diagrams contain both of these do they become 'constructive', they mediate between requirements and forms (Alexander, 1964: p.86-8). For Alexander the diagram is the starting point of design synthesis. This is not necessarily a form of determinism because there may be many forms that resolve any set of forces. The importance of the diagram to Alexander soon became apparent as it morphed into the concept of the pattern and ultimately the 'Pattern Language' for which he is most famous (Alexander et al, 1977).

Alexander's seminal paper 'A City is not a Tree' appeared in 1965, just a year after publication of 'Notes...'. Here he declares that the city should not be conceived in terms of hierarchy: "For the human mind, the tree is the easiest vehicle for complex thoughts. But the city is not, cannot, and must not be a tree. The city is a receptacle for life." (Alexander, 1965: 428). He mounts a powerful conceptual attack on architects and planners including Abercrombie, Hilberseimer, Costa, Le Corbusier, Tange, Soleri and the Goodmans for deploying tree-like thinking that damages the productive forces of the city by subsuming them to hierarchical control. He also implicitly abandons some of the tree-like thinking of his own earlier work. This critique largely stems from Alexander's understanding of the values of sociality in public space and the ways modernist zoning and overdetermination was stripping the city of complexities; in a later paper this became 
a quest to understand the city as a "mechanism for sustaining human contact" (Alexander, 1966). Within the 'City is not a Tree' paper Alexander tells a story about how one intersection in Berkeley works through random lateral interconnections; the hypothesis convinces, not because it is testable, but because it resonates with a multiplicity of experiences of everyday life in cities. Goodey (1982: 260) has argued that this paper needs to be seen as a nascent and interim work between 'Notes...' and 'A Pattern Language' where the 'diagrams' were reconceived as 'patterns'(Alexander et al, 1977).

The pattern is a set of forces coupled to a formal resolution geared to the aesthetics, materiality and sociality of architecture and urbanism. The patterns are linked together in a loose network that operates like a language leaving choices of which patterns to use and where. 'A Pattern Language' is a highly accessible book that remains a bestseller on Amazon and has had a huge impact in fields as disparate as new urbanism and computer software. While there are some attempts to test different patterns, this is scarcely science. As became apparent in 'The Timeless Way of Building' at the heart of Alexander's vision is a nebulous conception of 'wholeness' and the zen-like 'quality without a name' (Alexander, 1979). It is notable that while the 'city is not a tree' has become an uncontested adage of urban design theory, the 'pattern language' is widely contested and seen as over-prescriptive. There is no scope to explore such issues here, only to briefly note that that insights of the 'A City is Not a Tree' paper also resonate in 'A New Theory of Urban Design (Alexander, 1987) where the order of the city emerges from the piecemeal growth rather than master plans. This book has had little impact but can be seen as the beginning of a generative theory of urban design (Mehaffy, 2008). Ironically, it is Marshall (2009) who has developed the best account of such an evolutionary understanding of urban design to date; using similar diagrammatic thinking without empirical testing. Alexander's paper has become seminal because it was a moment of seminal clarity in our understanding of the city, but it was not exactly science.

\section{Urban Design Epistemologies}

So what are we to make of this cluster of theories and ideas? Our argument in summary is as follows: While the work of these six thinkers is not empirical science, it is based in detailed observations of real cities and has become seminal thinking in the field. Knowledge production in urban design spans across the humanities, social sciences and hard sciences; it is a particularly diagrammatic form of socio-spatial knowledge that cannot be reduced to words or numbers. Inasmuch as urban design is a science it must be considered a proto-science rather than a pseudoscience; it is linked to the sciences of probability, adaptation and complexity. Inasmuch as urban design cannot be reduced to science, it must be considered an assemblage of ideas where the interconnections matter more than ideas in themselves. The works of these six authors remain seminal more for the questions they open than the answers they provide. Science has no monopoly on knowledge production in urban design.

As a way of framing these questions of urban design epistemology we begin by examining the concepts of 'theory', 'knowledge', 'science' and 'empirical' as they apply to urban design. The concept of 'theory' is etymologically linked to 'theatre'; theory is a way of seeing the world through a particular lens while closing out others (Frow, 2005). In everyday terms theory is an explanatory framework that is defined in contrast with practice. 'Knowledge' is generally regarded as broader and more reliable than theory, as more than just a way of seeing the world. Knowledge is often integrated with practice; 'knowhow' is a capacity to get things done. Yet claims to knowledge are often contested by theory; as Foucault (1972) has shown, all knowledge is inextricably implicated in the knowledge/power regimes that produce it. 'Science' is generally understood as the form of knowledge that is derived from empirical testing, experimentation and observation based on inductive logic and quantification; it is often contrasted with the humanities where interpretation, argumentation and qualification prevail. Yet the term 'empirical' also has a broader meaning as that which is based on experience and observation, which is clearly the case with all of these thinkers. 
It is difficult to avoid the conclusion that the works we have considered here are empirical but are not science. These writers have observed the city over very long periods of time, measuring it where possible, and these observations crystalize into theory as a conceptual explanation of how the city works and, by implication, how it should be designed. None of the work discussed above either derives from or can be reduced to empirical science. Urban design theory and knowledge spans from the physical to the social sciences and humanities.

Science is generally linked to 'empirical' methods of inductive logic and empirical testing. Knowledge is seen to derive not from theory or doctrine but from the evidence of experience under controlled conditions. The problem with urban design knowledge is that there are no controlled conditions and very little urban design theory has emerged from the inductive logic of empirical science. Much of the theory outlined above uses deductive logic: a landmark is a dominant element of the urban image by definition; we can deduce that density and functional mix reduce travel distances and that short blocks provide greater walkable access. However, much of the logic of urban design thinking is neither deductive nor inductive but what Peirce originally defined as 'abduction' (Douven, 2011). The logic of abduction is a form of inference by 'best explanation' where a set of observations leads to a conjecture that explains them. It is a form of reasoning backwards from effect to cause by educated guesswork. The logic of abduction in urban design proceeds by observing the ways in which the city works and engaging in educated guesswork about how it works. The best of urban design theory, including that outlined above, has been educated by many years of observation. The greatest limitation is that it is grounded in the observation of formal western cities with huge gaps in our understanding of informal and eastern cities (Brillembourg and Klumpner 2005; Shelton, 2012). It remains guesswork not because the science of urban design is somehow lacking but because of the kind of problem a city is (Jacobs) - the complexity of interacting forces is too great for any science of certainty.

The important role of abductive logic in urban design theory opens the door to various kinds of ideology and prejudice. The urban experiences that Sitte and Cullen espouse are based on European morphologies; Lynch's elements are based on North American cities; and the minimum densities and block sizes proposed by Jacobs are effectively those of Greenwich Village. However, this infection of urban design knowledge by ideology and prejudice reflects the ways that urban design knowledge emerges - by detailed and protracted observation of a particular range of cities. There simply are no typical or universal cities one might study.

Urban design knowledge is of a different order to that of numbers and words; while it generally relies on both numbers and words it also relies strongly on diagrams. Sitte, Cullen, Lynch, and Alexander's work all brings diagrammatic thinking to the forefront in a manner that is more than simply illustrative. Jacobs' discussion of concepts such as mix, short blocks, density, grain size and pools of use are forms of diagrammatic thinking. A diagram is an abstract graphic representation of a set of forces that generally embodies spatiality, temporality and sociality. Diagrammatic thinking meshes well with urban thinking because it can show the ways in which a city works, abstracted from the particularities of singular places yet geared to the sociality and spatiality of the city.

The seminal urban design theory from the 1960s cannot be considered pseudo-science since there is very little claim to science in this work. None of it proceeds from hypothesis to inductive testing and the logic deployed is a mix of deduction, induction and abduction. The language of communication incorporates words, numbers and diagrams with a strong use of case study and thick description. There is, however, the question of whether urban design might be considered a proto-science that remains in nascent form, emerging from a constellation of disciplines: the sciences of complexity and complex adaptive systems on the one hand and the social sciences such as sociology, psychology, anthropology and political economy on the other. We suggest that inasmuch as urban design incorporates science then it is in a proto-phase. Yet there can be no science of urban design without reducing the city to its quantitative dimensions. The part that 
science can reveal is important but has no monopoly on urban design knowledge. To understand the city requires an interconnection of sciences and humanities. To allow the measureable parts of cities to become the determinants of change is to risk killing urban vitality.

As suggested earlier, both Jacobs and Alexander were influenced in their thinking by the emerging systems theory, cybernetics and information sciences of the mid $20^{\text {th }}$ century. There is now an emerging science of cities that is making considerable ground in understanding how cities work (Bettencourt et al, 2007; Batty, 2013), much of it based in theories of complex adaptive systems, self-organization, emergence and resilience (Walker and Salt, 2006; Gunderson and Holling, 2002). While based in the quantitative metrics of science, such theory shows how randomness, self-organization and adaptation play a key role in the productiveness and emergent identities of cities, and that outcomes are probabilistic at best. There are good reasons to develop better metrics for understanding and mapping those aspects of urban design where measurability is possible, as we have proposed in relation to concepts of density and walkable access (Dovey and Pafka, 2014; Pafka and Dovey, forthcoming). Yet the quest to define concepts such as 'walkability' soon leads to deep complexities - paving, safety, noise, light, permeability, functional mix, network integration, aesthetics, sociality, crowding, topography, climate and shelter are all key and intersecting variables, not all of which are quantifiable. The reduction of the city to its measureable components always comes at a cost and central to what is lost are the lived intensities, rhythms and socialities of everyday urban life (Lefebvre, 2004). Urban design thinking needs approaches that cut across dichotomies between objective and subjective, between materialities and representations, between science and humanities. One way to address this is to join sciences of complexity and adaptation to the social theory framework of assemblage thinking with its focus on the productive flows, synergies and alliances between things rather than things in themselves (Deleuze and Guattari, 1987; DeLanda, 2011). Such an approach to the city as a complex and adaptive assemblage of interconnections can be found in the seminal work of Alexander and Jacobs in particular. The task is to raise such thinking to a higher level, linking the humanities to the sciences, spatiality to sociality. To bring the science and social theory of cities together is an approach that might be labelled a 'complex adaptive assemblage' (Dovey, 2012).

In the end urban design theory, like public space, is a contested space. Unlike the sciences it is not decided in the court of scientific opinion, although some aspects will be. Unlike the humanities it is not decided by facts or interpretations, although some aspects will be. The forms of knowledge produced by the humanities are less certain but certainly broader than those of empirical science. It is of the nature of urban design theory to straddle these fields. It is not a separate form of knowledge, although it is characteristically diagrammatic, drawing interconnections between the materialities of urban space and the socialities of urban life. Knowledge, for Socrates, was found not in the fixed outcomes of a debate but in its very modes of contestation and questioning - in the new questions it opens up, in overcoming the illusions of certainty. Knowledge is to be found in understanding that we don't know; in no field is this more pertinent than in the study of urban design.

\section{References}

Alexander, C. (1964) Notes on the Synthesis of Form. Cambridge: Harvard University Press.

Alexander, C. (1965) A city is not a tree. Architectural Forum (172 April/May).

Alexander, C. (1979) The Timeless Way of Building. New York: Oxford University Press.

Alexander, C. (1987) A New Theory of Urban Design New York: Oxford University Press.

Alexander, C., Ishikawa, S., and Silverstein, M. (1977) A pattern language: towns, buildings, construction. New York: Oxford University Press.

Arnheim, R. (1954) Art and Visual Perception. Berkeley: University of California Press.

Ashby, R. (1960) Design for a Brain. New York: Wiley.

Barcelona, C.C. (2010) Cerda and the Barcelona of the Future. Reality versus Project. Barcelona.

Batty, M. (2013) The New Science of Cities. Cambridge, MA: MIT Press. 
Baumeister, R. (1876) Stadt-erweiterungen in technischer, baupolizeilicher und wirtschaftlicher Beziehung. Berlin: Ernst \& Korn.

Bettencourt, L.M.A., Lobo, J., Helbing, D., Kühnert, C., and West, G.B. (2007) Growth, innovation, scaling, and the pace of life in cities. Proceedings of the National Academy of Sciences of the USA, 104(17): 7301-7306.

Brillembourg, A. and Klumpner, H. (2005) The Informal City. Munich: Prestel.

Cerdá, I. (1867) Teoria General de la Urbanizacion. Madrid: Imprenta Española.

Choay, F. (1997) The rule and the model : on the theory of architecture and urbanism. Cambridge, MA: MIT Press.

Cohen, S. and Sherrod, D.R. (1978) When density matters: environmental control as a determinant of crowding effects in laboratory and residential settings. Journal of population, 1(3): 189202.

Collins, G.R. and Collins, C.C. (1965) Camillo Sitte and the Birth of Modern City Planning. New York: Random House.

Cullen, G. (1961) Townscape. London: Architectural Press.

Cullen, G. (1991) Townscape. Das Vokabular der Stadt. Basel: Birkhäuser.

DeLanda, M. (2011) Philosophy and Simulation. London: Continuum.

Deleuze, G. and Guattari, F. (1987) A Thousand Plateaus. Minneapolis: University of Minnnesota Press.

Douven, I. (2011) Abduction. In E.N. Zalta (ed.), Stanford Encyclopedia of Philosophy

Dovey, K. and Pafka, E. (2014) The urban density assemblage: Modelling multiple measures. Urban Design International, 19(1): 66-76.

Dovey, K. (2012) Informal Settlement and Complex Adaptive Assemblage, International Development Planning Review, 34 (3) 371-90.

Foucault, M. (1972) The archaeology of knowledge. New York: Pantheon Books.

Frow, J. (2005) Theory. In: T. Bennett, L. Grossberg, and M. Morris (eds.) New keywords : a revised vocabulary of culture and society: Malden, MA: Blackwel.

Gomrich, E. (1960) Art and Illusion. London: Phaidon

Goodey, B. (1982) Cut Down to Size? Christopher Alexander's 'A City is Not a Tree'. Built Environment, 8(4).

Gosling, D. (1996) Gordon Cullen: Visions of Urban Design. London: Academy Editions.

Gunderson, L. and Holling, C. (2002) Panarchy, Washington: Island Press.

Hillier, B. and Hanson, J. (1984) The social logic of space: Cambridge University Press.

Hoek, J.W.v.d. (2008) The MXI (Mixed-use Index) as Tool for Urban Planning and Analysis. Paper presented at the Corporations and Cities: Envisioning Corporate Real Estate in the Urban Future, Delft University of Technology.

Isaacs, R. (2000) The Urban Picturesque: An Aesthetic Experience of Urban Pedestrian Places. Journal of Urban Design, 5(2): 145-180.

Jacobs, J. (1961) The death and life of great American cities. New York: Random House.

Kepes, G. (1944) Language of vision. Chicago: Paul Theobald.

Lampugnani, V.M. (2012) Gedächtnis und kritische Wissenschaft - Für eine Neugründung der Disziplin Städtebau. Geographische Revue, 14(1): 53-57.

Larice, M. and Macdonald, E. (2013) Editors' introduction to The Concise Townscape. In: M. Larice and E. Macdonald (eds.) The Urban Design Reader: Routledge, pp. 118-119.

Ley, K. (2007) Die Intellektualisierung des Städtebaus in Deutschland: Schriften zum Städtebau und das Entstehen einer wissenschaftlichen Disziplin im späten 19. Jahrhundert. RWTH Aachen

Lynch, K. (1960) The Image of the City. Cambridge MA: MIT Press.

MacArthur, J. (2007) The Picturesque. London: Routledge

Marshall, S. (2009) Cities, design \& evolution: Routledge.

Marshall, S. (2012) Science, pseudo-science and urban design. Urban Design International, 17(4): 257-271.

Mehaffy, M.W. (2008) Generative methods in urban design: a progress assessment. Journal of Urbanism, 1(1): 57-75. 
Mitchell, R.E. (1971) Some Social Implications of High Density Housing. American sociological review, 36(1): 18-29.

Nes, A., Berghauser Pont, M., and Mashhoodi, B. (2012) Combination of Space Syntax with Spacematrix and the Mixed Use Index. The Rotterdam South test case. Paper presented at the 8th International Space Syntax Symposium, Santiago de Chile.

Pafka, E. (2013) Nothing Gained by only Counting Dwellings per Hectare: A Hundred Years of Confusing Urban Densities. Paper presented at the State of Australian Cities Conference, Sydney.

Pafka, E. and Dovey, K. (forthcomming) Permeability and Interface Catchment: Measuring and Mapping Walkable Access.

Rapoport, A. (1990) History and Precedent in Environmental Design: Springer.

Rapoport, A. and Kantor, R.E. (1967) Complexity and Ambiguity in Environmental Design. AIP Journal, 33(4): 210-221.

Schmidt, C.G. (1977) Influence of Land Use Diversity Upon Neighbourhood Success: An Analysis of Jacobs' Theory. Annals of Regional Science, 11(1): 53-65.

Serratosa, A. (1999) Foreword. In: A. Soria y Puig (ed.) Cerdá: The Five Bases of the General Theory of Urbanization: Madrid: Electa, pp. 13-19.

Shelton, B. (2012) Learning from the Japanese city: looking East in urban design: Routledge.

Simone, A. (2010) City Life from Jakarta to Dakar. London: Routledge.

Sitte, C. (1889) Der Städtebau nach seinen künstlerischen Grundsätzen. Vienna: Graeser.

Smith, P.F. (1974) The Dynamics of Urbanism. London: Hutchinson.

Soria y Puig, A. (ed.) (1999) Cerdá: The Five Bases of the General Theory of Urbanization. Electa: Madrid.

Stübben, J. (1890) Der Städtebau. Darmstadt: Bergstrasser.

Walker, B. and Salt, D. (2006) Resilience Thinking, USA: Island Press

Weicher, J.C. (1973) A Test of Jane Jacobs' Theory of Successful Neighbourhoods. Journal of Regional Science, 13(1): 29-40.

Weiner, N. (1948) Cybernetics. Cambridge, Ma.: MIT Press.

Wilhelm, K. (2006) Ordnungsmuster der Stadt. Camillo Sitte und der moderne Städtebaudiskurs. In: K. Wilhelm and D. Jessen-Klingenberg (eds.) Formationen der Stadt: Camillo Sitte weitergelesen. Basel: Birkhäuser, pp. 15-96. 